\title{
EXPEDIÇÃO PEDAGÓGICA E COLETIVOS DOCENTES NA AMÉRICA LATINA: OUTROS MODOS DE FORMAÇÃO
}

\author{
MORAIS, Jacqueline de Fátima dos Santos ${ }^{1}$
}

\section{RESUMO}

Este texto buscar e memorar uma experiência vivida no e com o Núcleo de Pesquisa e Extensão Vozes da Educação - História e Memória das Escolas de São Gonçalo denominada Expedição Pedagógica. Esta atividade aconteceu na cidade de Neuquén, Argentina, entre os dias 23 e 27 de maio de 2012, com docentes da Venezuela, de Argentina e Brasil. 0 artigo trata de discutir o conceito de Expedição Pedagógica ao mesmo tempo que discute os atravessamentos experimentados pela autora durante essa atividade. Apoiada especialmente no filósofo Walter Benjamin, a autora reflete sobre a importância de não deixar as experiências caírem no esquecimento, algo frequente na modernidade. $O$ texto defende a viagem como um potente recurso de formação docente.

PALAVRAS-Chave: Coletivos docentes - Expedição pedagógica - Formação docente.

\begin{abstract}
This text seeks to recall na experience lived in and with the Núcleo de Pesquisa e Extensão Vozes da Educação - História e Memória das Escolas de São Gonçalo called Pedagogical Expedition. This activity took place in the city of Neuquén, Argentina, between May 23 and 27, 2012, with teachers from Venezuela, Argentina and Brazil. The article discusses the concept of Pedagogical Expedition while discussing the crossings experienced by the author during this activity. Supported especially by the philosopher Walter Benjamin, the author reflects on the importance of not letting the experiences fall into oblivion, something common in modernity. The text defends travel as a potent teacher training resource.
\end{abstract}

KEYWORDS: Teaching collectives - Pedagogical expedition - Teacher training.

\footnotetext{
${ }^{1}$ Professora Adjunta da Faculdade de Formação de Professores da Universidade do Estado do Rio de Janeiro (FFP/UERJ). Email: jacquelinemorais@hotmail.com
} 
La vida no es la que uno vivió, sino la que uno recuerda y como la recuerda para contarla

(García Márquez)

\section{Primeira paisagem: O Sentido do texto}

Inicio este texto tomando as palavras do escritor colombiano Gabriel Garcia Marques no intuito de, com elas, anunciar o que me proponho neste artigo: rememorar uma experiência vivida no e com o Núcleo de Pesquisa e Extensão Vozes da Educação - História e Memória das Escolas de São Gonçalo "como la recuerdo para contarla". Isto significa que não me habita a pretensão de produzir uma narrativa última e irrepreensível do que se conhece na América Latina por Expedição Pedagógica e que tivemos a oportunidade de viver na cidade em Neuquén, Argentina, entre os dias 23 e 27 de maio de 2012, com docentes da Venezuela, de Argentina e Brasil.

Apoio-me na ideia de que narrar é, de certa forma, ficcionar o vivido e, inspirada em Benjamin (1996), de que escrever sobre o vivido "não significa conhecê-lo como ele de fato foi. Significa apropriar-se de uma reminiscência, tal como ela relampeja no momento de um perigo" (BENJAMIN, 1996, p. 225). Como mirar e dizer sobre uma experiência vivida, sabendo que o discurso não é capaz de recobrir com palavras o experimentado na vida? Sabendo ainda que meu dizer encontra limites inúmeros? Afinal, como narrar 0 que "relampeja no momento de perigo"algo que se dá a ver em poucos segundos, por imagens rápidas, por clarões em fugas? Por outro lado, como não contar? Como ignorar, ser indiferente a uma reminiscência que desejaria transcender da memória pessoal e ser apropriada por outras pessoalidades?

Este texto, portanto, além de me convidar a caminhar em direção ao que vivi como atividade coletiva com o Grupo Vozes da Educação, me desafia a não me deixar ser cúmplice do esquecimento. A não deixar para traz, pelo caminho do esquecimento, as riquezas que na docência como um campo de práticas e saberes, vivemos juntos em terras argentinas.

Por outro lado, ainda sob a influência do autor que me acompanha no esforço de (re)encontrar e (re)escrever o vivido, Walter Benjamin, me dou conta de que, ao recordar a Expedição Pedagógica que se deu em Neuquén, os lugares pelos quais passei, as pessoas que conheci, os diálogos que travei, o tempo se converte em uma não-linearidade: em nada aparece vazio e, nele, uma sequência de planos e retas. Ao contrário: minhas recordações adquirem sinuosidade. Terei assim um passaporte que me permite caminhar por onde quero, por trilhas e trajetórias que mais me apetecem neste texto, sem ser cobrada de um texto que dê conta da totalidade da experiência em Neuquén? Rogo que sim. Para tal, valho-me da narrativa que "não está interessada em transmitir o puro de si da coisa narrada como uma informação ou um relatório" (BENJAMIN, 1996, p. 205), mas que se alegra e se nutre da ação de compartilhar impressões de uma viagem construída e vivida como um projeto coletivo. Dentre esses coletivos, nomeio alguns: Rede de Docentes que hacen Investigacion Educativa (Red DHIE), Asociación de Trabajadores de La Educación (ATEN), Instituto Superior de Formación Docente $n^{\circ} 9$ Paulo Freire (ISFD), Núcleo de Pesquisa e Extensão Vozes da Educação - História e Memória das Escolas de São Gonçalo.

Portanto, o que me move à escrita deste artigo, buscando coerência com o dizer de Benjamin, é rememorar uma experiência. Experiência que não se reduz, como nos adverte este mesmo autor, a mercadoria, já que não pode ser qualificada e quantificada por certa temporalidade. 
Não tem mais experiência um homem de 50 que um de 30 . Não é menos experiente uma professora recém concursada que uma prestes a assinar sua aposentadoria.

Assumo, dessa forma, um texto atravessado por punhados de incongruências, afetações, lembranças seletivas, esquecimentos, falhas na linearidade dos acontecimentos. Afinal, "contar seguido, alinhavado, só mesmo as coisas de rasa importância" (ROSA, 1982, p.78). O que me habita como acontecimento vivo, intenso, pulsante, vai cruzando a lembrança em ritmo próprio, atropelando a temporalidade da narrativa em assaltos e sustos, criando tempos e sequências de certo modo originais.

Meu texto tematiza, assim, o que para mim se constitui como uma fértil experiência, no sentido que lhe atribui Larrosa: como aquilo que nos acontece e não simplesmente como aquilo que acontece (LARROSA, 1999). Escrevo, desta forma, sobre algo que em mim fez morada e produziu efeitos que se espraiam ainda hoje, me convidando a revisitar este tempolugar. A não sucumbir à Amnésia social.

Atravessada por recordações de uma experiência intensamente vivida e profundamente formativa, sinto ainda ecoarem certas perguntas: "Qual a importância da Expedição Pedagógica vivida em Neuquén para o conjunto de professores do Vozes da Educação? ${ }^{\prime \prime \prime} Q u e$ repercussões trouxe para nossos que fazeres pedagógicos?" "Como avaliar a importância de uma experiência como a que vivemos na Argentina?" "É possível tal pretensão? "Algumas respostas são melhor encontradas no campo da poesia.Como nos adverte o poeta Manoel de Barros "a importância de uma coisa não se mede com fita métrica nem com balanças nem barômetros etc. Que a importância de uma coisa há que ser medida pelo encantamento que a coisa produza em nós" (BARROS, 2010, p. 109). Portanto, este texto se constitui menos como uma síntese de graus de mensura- ção de um ou outro aspecto do que seja uma Expedição Pedagógica e mais como um acerto de contas, uma forma de retribuir, ou talvez um jeito de celebrar, aquilo que planejamos e realizamos coletivamente, brasileiros, argentinos e venezuelanos, numa dada circunstância e tempo histórico. Talvez seja também um modo de não deixar o esquecimento se apoderar da vida vivida na generosidade e no encontro.

Tomo a Expedição Pedagógica que vivemos em Neuquén como centralidade deste artigo, portanto, levando em conta a potência desta atividade como alternativa política-pedagógica de formação docente no âmbito latino-americano e a rica experiência que nos permitiu viver. É preciso lembrar, no entanto, que os processos educativos na América Latina se produzem em meio a processos de disputa hegemônica na região. As políticas educativas não são imunes aos processos sociais, econômicos e políticos complexos e contraditórios mais amplos. As reformas estruturais do Estado que vem ocorrendo em toda a América Latina implicam reformas no campo educativo em favor, especialmente, de alinhamentos à agenda neoliberal (OLIVEIRA e FELDFEBER, 2015). Os mecanismos de regulação, no entanto, não ocorrem sem luta. Entendemos que experiências como a Expedição Pedagógica, tal como vivida por nós no contexto argentino, pode ser compreendida como uma forma de luta contra hegemônica.

Desafio-me, assim, a escrever menos o que passou no outono de 2102 na cidade de Neuquén e mais como me passou (LARROSA, 2002) entendendo que é nosso compromisso lutar contra o desperdício da experiência (SANTOS, 2000). Entendo que o desperdício da experiência, do qual trata Santos, se produz em função da sua pouca visibilidade. Assim, escrever sobre uma experiência específica, vivida com certos professores latino americanos, em um contexto comunitário específico, marcado por inúmeros desafios e diferen- 
ças individuais e coletivas, me ajuda a reinventar a vida e a ressignificar a formação docente. Viver por quase uma semana entre colegas de diferentes localidades, me permitiu experimentar diferenças sociais, culturais e políticas, expressas, dentre outros modos,em maneiras de comer, dormir, vestir, beber, dizer. Ao mesmo tempo forjou o desejo de superar as divergências e antagonismos- o que nem sempre ocorreu em desconforto - em favor de negociações possíveis, emergindo daí possibilidades de novas práticas e novos conhecimentos e, portanto, de subjetividades mais solidárias.

A experiência vivida através da Expedição Pedagógica não é um modelo a ser replicado em todos os lugares como a solução para a suposta crise na formação docente. Sua positividade para mim se assenta na riqueza expressa na produção de processos e conhecimentos pedagógicos de natureza latina, na criação e visibilidade de modos alternativos de investigar e educar, modos que põem em questão maneiras ortodoxas de viver e produzir a formação e a investigação no campo educativo. A Expedição Pedagógica, como uma ferramenta de formação docente, cria um ambiente para a vivência de práticas de solidariedade, estabelecimento de diálogos multiculturais, ações nas quais conhecer o outro possibilita autoconhecimento e, portanto, a emergência de conhecimento-emancipação.

\section{SEgunda PAISAgeM: MINHA CHEgAdA AO VOZES DA EDUCAÇÃo}

Participo como pesquisadora do Núcleo Vozes da Educação desde minha entrada como professora do Departamento de Educação da Faculdade de Formação de Professore, em São Gonçalo. Não sei exatamente como se deu minha inclusão neste grupo. Tenho frágil memória para datas e números. Sei, isto sim, que minha decisão se deu pelas afinidades com parte das pesquisadoras que lá já se encontravam, em especial com Mairce da Silva Araújo e Maria Tereza Goudard Tavares, e pela identificação com os princípios que atravessam a história do Vozes.

Nossa história como grupo de Pesquisa e Extensão evidencia uma trajetória construída a partir de ações que articularam um grupo de professores(as) pesquisadores(as) da FFP/UERJ e escolas da rede gonçalense, sindicatos, movimentos sociais, estudantes e bolsistas em um caminho de permanente construção/reconstrução (MORAIS, ARAÚJO, ALVARENGA, TAVARES, 2011, p.41).

Ao ser aprovada como docente da UERJ no ano de 2007, já conhecia estas colegas através de minha inserção no grupo de pesquisa "Alfabetização das Crianças das Classes Populares", na Universidade Federal Fluminense, coordenado por Regina Leite Garcia. Lá, a cada sexta feira, nos encontrávamos, renovando compromissos políticos e epistemológicos com a alfabetização de todos e todas. Assim, a escolha pelo Grupo Vozes parecia coerente e natural quando passei a ocupar o espaço da Faculdade de Formação de Professores e a me perguntar: que compromissos políticos estão implicados em ser docente em São Gonçalo? O que significa pesquisar a educação que se realiza nas escolas em São Gonçalo? O grupo de pesquisa Vozes da Educação foi me ajudando a construir algumas repostas e inúmeras outras perguntas.

Uma vez neste espaço, a aproximação com outras colegas foi se dando e, consequentemente, a construção de projetos compartilhados: seminários, oficinas, trabalhos de investigação, escrita de artigos há muitas mãos, movimentos de luta em tantos momentos de greve. 


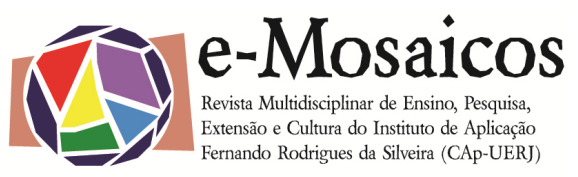

alunos(as) e professores(as) em um permanente diálogo com acidade de São Gonçalo (MORAIS, ARAÚJO, ALVARENGA， TAVARES，2011， p.40). rência marcante o diálogo com acidade de São Gonçalo. A afirmação do elo coma cidade e com a sua educação colaborou com a escrita da história do "Vozes" e com a produção de um conhecimento que articula memória, história e formação docente (MORAIS, ARAÚJO, ALVARENGA, TAVARES, 2011, p.40).

Em um mundo que parece caminhar em movimentos contraditórios: pela busca da celebração da memória, por um lado, e pelo triunfo do esquecimento, por outro, lembrar os nomes que marcaram a origem do Vozes, representa a defesa de que "nada do que um dia aconteceu pode ser considerado perdido para a história" (BENJAMIN, 1996, p. 223). Portanto, é preciso nomear quem esteve na origem do Vozes: Haydèe Figueiredo, Martha Hees e Maria Tereza Goudard Tavares, apontando o ano de 1996 como marco. Marco também de lançamento da $1^{a}$ edição do livro de Paulo Freire "Pedagogia da autonomia: saberes necessários à pratica educativa". Assim, comungando com a ideia de Freire (1996) de que "não há ensino sem pesquisa e pesquisa sem ensino" (FREIRE, 1996, p. 32), estas companheiras instituíram o primeiro grupo de pesquisa do então Departamento de Educação da Faculdade de Formação de Professores, defendendo a ideia de que pesquisar é um ato político no qual conhecer implica necessariamente compartilhar o resultado das indagações. Para isso, é preciso, ainda inspirados em Freire (1996), nos percebermos e nos assumirmos porque professores, pesquisadores.

O Vozes, ao longo do tempo

Vem desenvolvendo diferentes ações de ensino-pesquisa-extensão buscando constituir espaços de memória, narração e formação para
Sabemos, no entanto, que as universidades, e os grupos de pesquisa por consequência, vivem desafios quanto a sua legitimidade como lócus privilegiado de produção de conhecimento. Na análise de Buarque, esta crise de hegemonia estaria "na perda da capacidade para definir corretamente os problemas aos quais a formação e as pesquisas devem servir" (BUARQUE, 1994, p.225). Nesse sentido, são urgentes e atuais perguntas como: o que, para que, para quem e como devemos produzir e socializar conhecimentos produzidos no campo da pesquisa?

A trajetória de 15 anos do Vozes da Educação não está marginal a essas questões. Em diálogo com grupos e movimentos sociais, sindicatos, espaços educativos, escolas, outros grupos de pesquisa, instâncias educativas de todo tipo, essas perguntas sempre fizeram parte das ações e projetos do Vozes, entendendo que todo projeto de pesquisa é também um projeto político.

Dessa forma, a criação e a trajetória do Vozes da Educação está consonante a um projeto de sociedade mais solidária, comprometida e crítica.

\section{Terceira paisagem: A Expedição Peda- GÓGICA EM NEUQUÉN}

Dos muitos momentos intensos que vivi no Vozes, um se destaca: a experiência de Expedição Pedagógica ocorrida como parte do Encontro "Voces sobre educación. Practicas educativas de Venezuela, Brasil e Argentina. Relatos compartidos", integrando educadores/as brasileiros/as, argentinos/as e venezuelanos/as. Tanto o Encontro, quanto a Expedição 
Pedagógica decorrente deste, foram levados a cabo em Centenário, província de Neuquén, Argentina, entre os dias 21 e 27 de maio de 2012.

Participaram dessa Expedição Pedagógica, não apenas como viajantes expedicionários, mas como organizadores da ação, vários grupos. Dentre eles destaco: docentes e alunos do Instituto Superior de Formación Docente (ISFP) No 9 Paulo Freire, localizado em Centenario, sendo sede de nosso encontro. Outro grupo organizador dessa Expedição foi o de educadores e educadoras da Escuela Social Rodrigueana de Latinoamérica y el Caribe, originários da Venezuela. Por fim, nós, ao todo dez educadores/as brasileiros/as: Cleise Campos, Petronilha Silva, Sandra Lacerda, Ana Ayres, Luiz Dorvillé, Marcia Alvarenga, Maria Tereza Tavares, Mairce Araújo, Jacqueline Morais e Inês Bragança. Destes, oito, oriundos da Faculdade de Formação de Professores de São Gonçalo, sendo que os últimos seis nomes, pertencentes ao Grupo Vozes da Educação.

Três países, três territórios, muitos sujeitos.

Para vivê-la era necessário compreender tal proposta. Afinal, o que seria uma Expedição Pedagógica? Que funções exerceriam no campo educativo? Que provocações e desafios nos trariam?

Unda Bernal, Martínez e Mejía (2002), referências quando se trata de Expedições Pedagógicas, nos dizem que são movimento de professoras e professores que, por meio de deslocamentos territoriais visam gerar deslocamentos nos modos de compreender os fazeres pedagógicos. Dizem os autores que as Expedições Pedagógicas:

Combinando la movilización social por la educación y la construcción colectiva de una mirada sobre la diversidad y la riqueza pedagógica, ha consistido en un amplio desplie- gue de desplazamientos físicos por nuestras regiones, pero sobre todo en una serie de desplazamientos em el orden del pensamiento, pues se ha producido un encuentro con las más variadas y singulares prácticas pedagógicas realizadas por maestros que, como ellos, intentan afirmar posibilidades de vida distintas, desde la escuela (BERNAL, MARTINÉZ, MEJÍA, 2002, p. 1).

Assim, as Expedições buscam a emergência de práticas e saberes docentes muitas vezes invisibilizados, produzidos em condições nem sempre favoráveis, mas que podem revelar a escola em sua pulsão de vida, problematizando, enfim, a ideia da instituição educativa como mero lócus de produção do fracasso, marcado pela repetição sem sentido, pelo ensino memorialístico, pela educação bancária há muito denunciada por Freire (1996). Nas rotas das Expedições, vamos em busca de uma escola que se reconheça como lugar de produção de uma educação outra, que não se conforma com um lugar silenciado mas que se afirma como potência. Uma escola que não compactua com o olhar opaco contra a escola. Que não aceita o "desperdício da experiência" (SANTOS, 2000, p. 34), sua e das demais escolas que formam o campo educativo. Para tanto, nos diz Forero:

La EPN (Expedición Pedagógica Nacional) em Colombia, es un movimiento de formación, autoformación y producción de saber Pedagógico. La forma específica de formación em el movimiento se desarrolla a partir del viaje como un seminario de formación permanente para los expedicionarios, y para todo aquel maestro que desee convertir el aprendizaje de una aventura matizada de diferentes componentes como son la investigación, 
la exploración y el conocimiento (FORERO, 2011, p. 2).

As viagens que constituem as Expedições Pedagógicas geram encontros de todo tipo e estimulam a construção de olhares sobre si mesmos e sobre a multiplicidade de concepções e práticas pedagógicas.

\begin{abstract}
Viajar implica anticiparse, moverse, salir del sitio, emprender una acción; viajar reclama goce, disfrute, placer; Por tanto viajar em la EPN significa mucho más, que tener unas coordenadas conceptuales básicas de orden teórico y metodológico, que permitan orientar y explorar sin perder la capacidad de asombro, por lo imprevisto, por aquellas cosas que no nos hemos detenido a pensar y a reflexionar (FORERO, 2011, p. 2).
\end{abstract}

As viagens por certos rotas e territórios, os encontros com outros docentes e estudantes, são vividos como experiências situadas, conectadas a localidades específicas, com condições de vida concretas, a partir da ideia do reconhecimento dos professores e professoras como sujeitos políticos. Afinal...

El viaje en Expedición Pedagógica es dinámico es movilización, movimiento, es interrogación a preguntas que mediante la reflexión da lugar a nuevas preguntas, porque constantemente se está evaluando sobre el cómo y para que se viaja. Es un viaje por las escuelas de nuestro país y por el pensamiento para la producción de saber pedagógico (FORERO, 2011, p. 2).

As Expedições Pedagógicas são um convite a desbravar o lugar destituído da curiosidade folclórica, que vê o outro como objeto. A viagem, mais que um arrasto físico, pode ser compreendida como um deslocamento do pensamento, que nos convida a reconstrução do olhar sobre a escola e os professores e professoras.

Na América Latina, esta ação teve sua origem no Movimento Pedagógico na Colômbia nos anos 80 e foi se fortalecendo ao longo dos anos. A participação de docentes da Universidade Pedagógica Nacional no movimento que ora surgia, resultou na elaboração de um projeto que,ao ser apresentado ao Ministério de Educação Nacional, redundou em sua aprovação como política pública de formação para todo o país, constituindo parte do Plano Decenal de Educação que vigoraria entre os anos 1996-2005. Estima-se que cerca de 290 organizações educativas até hoje tenham participado de Expedições Pedagógicas, nos diferentes âmbitos: local, regional, nacional e internacional. Já foram publicados vários livros e artigos, bem como produzidos vários vídeos que mostram a experiência vivida em várias rotas.

Para Arcuri e Romero (2014) não podemos entender as características desta modalidade de produção de conhecimento pedagógico se não compreendemos a Expedição Pedagógica como:

Una propuesta de formacióninvestigación participativa, que reivindica los desplazamientos de educadores/as, en diferentes territorios, para conocerlo que otros/as hacen y las razones de su accionar, considerando el suelo que habitan, como fundamento que sustiene sus trabajos (ARCURI, ROMERO, 2014, p. 12).

Os deslocamentos físicos permitem conhecer a riqueza pedagógica de escolas situadas em geografias outras. De intercambiar práticas e saberes com docentes que, de outro modo, talvez não se pudes- 
se. De aprender a partir de distintos modos de ser professor e de fazer escola.

A experiência de fazer parte da Expedição Pedagógica em Neuquén nos desafiou a viver os diferentes territórios como um lugar pedagógico já que

Las expediciones propuestas em el encuentro con compañeros/as de Venezuela, Brasil y Argentina, fueron una invitación a explorar los territorios escolares de la localidad pero también otros territorios, también pedagógicos pero no tan reconocidos como tales. Así, las ciudades de Centenario y de Neuquén fueron presentadas a la mirada y los cuerpos de los/as visitantes, como territorios de memoria (ROMERO, 2014, p. 9).

Não é consensual a ideia de que percorrer longínquas localidades seja uma rica experiência e importante instrumento de formação docente. Uma mirada histórica basta para constatarmos que a mobilidade física esteve associada a vidas marginais. Os que saiam de sua terra em busca de outras eram visto, em geral como andarilhos, vagabundos, migrantes, refugiados, nômades.

É no século XIX, com a Constituição dos Direitos Humanos, que a mobilidade física será identificada com a ideia de liberdade e que turistas e vagabundos serão categorias diferenciadas e hierarquizadas. Hoje, a ideia da viagem como instrumento de formação já se vê como mais consensual.

No Brasil, pelos idos de 1925, Anísio Teixeira, então Diretor Geral de instrução da Bahia, realiza inúmeras viagens pedagógicas a Europa e Estados Unidos, a fim de conhecer métodos modernos de ensino bem como processos atualizados de formação docente, fazendo parte um movimento maior presente nos séculos IX e $X X$.
Assim, não podemos afirmar que a viagem como estratégia para conhecer certos campos e experiências educativas, seja algo novo. A novidade está na ideia de que os fazeres docentes locais não podem ter a pretensão de servirem de grandes modelos de ação.

\section{QUARTA PAISAGEM: AS ROTAS EM NEUQUÉN}

As Expedições Pedagógicas são possibilidades de vivermos a cidade como território educativo. Para tanto, a definição dos percursos a serem feitos pelo grupo de professores, é fundamental. Em geral, se elabora com a participação de todos, uma ou várias rotas, levando em conta espaços, tempos, quantidade de expedicionários que irão participar, espaços educativos que poderão receber os docentes viajores.

As rotas pedagógicas são traçadas com fins a marcar uma travessia, caminhos e percursos que buscam provocar não apenas o deslocamento dos corpos, mas em especial o do pensamento. Para tal:

Están compuestas por los proyectos, prácticas o actividades que des de la región se consideran como significativas, relevantes e innovadoras a nivel pedagógico/educativo y que aportan en la construcción y fortalecimiento de la educación pública, popular, democrática y emancipadora (IMEN, 2014, p.118).

As rotas permitem ao viajante conhecer o que se faz naquele território pedagógico, implicando necessariamente uma relação na qual o compartilhamento da sua experiência é uma via de mão dupla, enriquecendo desta forma, a todos.

Comienzan en el momento en que las comunidades toman la decisión de mostrar al grupo de expedicio- 
narios lo que hacen y compartirlo. Es decir, son sujetos (colectivos o individuales) que están dispuestos a reconocerlos aportes que desde la visita expedicionaria se realicen (IMEN, 2014, p.118).

Esta perspectiva põe em questão uma postura consumidora que marca certas práticas formativas em favor da ideia de que somos fundamentalmente produtores de práticas e saberes.

Em Neuquén, a rota pedagógica construída em parceria por anfitriões e expedicionários, nos permitiu atravessar e sermos atravessados pelos seguintes locais:

Confederación Mapuce de Neuquén;

Casa de las Madres de Plaza de Mayo filial Neuquén y Alto Valle;

Fabrica sin Patrones;

Biblioteca La Fonseca;

Sindicato Docente ATEN;

Senillosa, lugar onde foi assassinado o professor Carlos Fuentealba;

El Chocón.

Muitos dos lugares que visitamos tinham por objetivo acordar em nós a desconfiança sobre a história oficial, acendendo o desejo por buscarmos outras narrativas historiográficas. O que contam os Mapuce sobre o direito a terra e sobre a luta contra a violência do estado? 0 que dizem os docentes argentinos sobre a vida e a morte do professor Carlos Fuentealba? Como um grupo de operários ceramistas conseguiu fundar uma fábrica sem a presença de patrões? Como vive uma mãe que teve seu filho sequestrado e desaparecido pela ditadura militar argentina entre as décadas de 70 e 80 ?
Además, imaginamos un tiempo y un espacio para conocer, em terreno, instituciones, organismos y grupos que hacen de nuestro mundo, un mundo mejor para todos (ARCURI, ROMERO, 2014, p. 17).

A Expedição Pedagógica com sua rota especial nos convida a ressignificar o sentido de viajar e de ser docente. Quem visita e quem é visitado pode viver no encontro que se produz novas formas de ser e de agir. De ver e sentir. De produzir a docência e a discência.

Faz parte dos princípios da Expedição Pedagógica espaços de registro, análise e sistematização sobre o vivenciado no território. Escrever sobre as experiências vividas pode permitir potencializar o trabaIho docente e dar visibilidade a práticas pedagógicas alternativas.

Conhecer Neuquén através de tantas vozes me ensinou o que pode uma cidade quando sua história está vinculada a mobilizações populares em favor dos direitos humanos. Quando suas ruas estão marcadas pela memória das marchas organizadas em prol de um espaço urbano menos regulador e não emancipador. Quando a escola entende a cidade como espaço educativo. Quando a população se nega a esquecer o passado e exige justiça para os crimes de estado. Talvez por tudo isso e muito mais, tivemos a honra de habitar por uma semana a "capital dos direitos humanos", como seus habitantes a ela se referem.

\section{Última PAISAGEM: ALgUMAS CONSIDERA- ÇÕES FINAIS}

Ao acolher a temática deste artigo, fruto do apelo que faz o passado e sabendo que "esse apelo não pode ser rejeitado impunemente" (BENJAMIN, 1996, p. 223), uma certa arquitetura foi se configurando, visibilizada por dois traços mais fortes. Um 


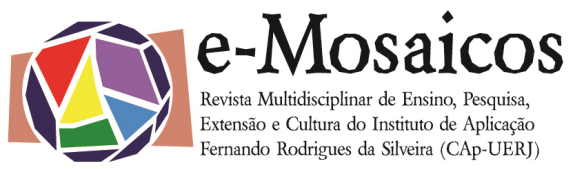

deles relacionou-se a necessidade de trazer no texto a intensidade vivida durante a chamada Expedição Pedagógica, o que tenho clareza, não consegui realizar. Outro aspecto que desejei abordar neste artigo, diz respeito ao conceito de Expedição Pedagógica, compreendida como uma maneira alternativa de formação docente. Busquei ao mesmo tempo, narrar sobre algumas das provocações que essa experiência produziu em mim. Assim, tentei organizar este texto através de caminhos que se bifurcaram e se atravessaram.

As Expedições Pedagógicas buscam afirmar professores e professoras como intelectuais, sujeitos portadores de saberes e não como meros destinatários de políticas definidas sem a participação docente. Possibilitam ver a educação por perspectivas outras e habitar o mundo a partir de outra ótica.

A riqueza do que vivemos entre os dias 23 e 27 de maio de 2012 em Neuquén, com professores e professoras originários da Venezuela, de Argentina e Brasil, me convida a agradecer as professoras argentinas Andrea Arcuri, Cecilia Iglesias, Silvia Juncos, Mirta Muñoz, Teresa Romero, Fermina Rivas, Graciela Martínez, Noemí Cavallini pelo empenho na realização da Expedição Pedagógica. Por outro lado, é também necessário o reconhecimento do esforço e liderança da professora Maria Tereza Tavares na concretização deste projeto.

Este texto carrega a utopia congregada na ideia de "nuestroamericana", vivida com um pequeno grupo e em um curto tempo. Nele, o desejo de que não tenha sido em vão.

Como afirma Lispector, "é do buscar e não achar que nasce o que eu não conhecia. (...) A linguagem é o meu esforço humano" (LISPECTOR, 1990, p.172). Esse esforço provocou em mim revisitar um tempolugar de intensidades e experiências, sabendo que escrever sobre ele era um projeto que se tecia mediante questões: o que posso (re)conhecer o que vivi? Como? Para quê? Até onde? Perguntas cujas respostas convidaram a um saber comprometido e nada ingênuo (FREIRE, 1996).

Escrever sobre o passado não é ir ao encontro de um tempo cerrado, mas sim aberto, que alimenta e se fortalece nos compromissos presentes. A experiência da viagem como espaçotempo de formação docente, conforme possível na Expedição Pedagógica pode ser metaforizada na ideia da ruína, utilizada tantas vezes por Benjamin. Nesse caso, ruína vista como vestígio do que se viveu e que permanece em partes, em fragmentos, permitindo reconfiguração, rearranjos, pistas de que algo passou e nos passou. As ruínas, compreendidas em sua positividade, nos ajudam a ver as brechas da história, a intensidade do instante, a permanência dos projetos coletivos.

Viajar pode por em xeque certa tradição acadêmica que afirma, desde muito, o valor do conhecimento como fixidez, permanência, certeza, verdade. É preciso, portanto, levar em conta como afirma Morin $(2000$, p. 86) que "o conhecimento é, pois, uma aventura incerta que comporta em si mesma, permanentemente, o risco de ilusão e de erro". Situações que vivi durante a Expedição Pedagógica, como parte da experiência de estar em viagem à Neuquém: procurar um banheiro e deparar-se com uma placa onde se lia "baño" e pensar que ali era lugar apenas de banhar-se. E seguir procurando a placa "certa". Ou ainda estando com fome e diante de inúmeros bolos maravilhosos, dizer que queria uma torta e ver o funcionário trazer um sanduíche. Aprendizagens: os sentidos locais das palavras precisam ser aprendidos e todo conhecimento provoca e revela processos de autoconhecimento. Isto significa compreender que "o conhecimento não é um espelho das coisas ou do mundo externo" (MORIN, 2000, p. 20), mas so- 
mente negociações e traduções de certa realidade. Essa ideia implica reconhecer que todo conhecimento é produto de seu tempo e lugar. É histórico, portanto. E bem que poderia ter sido outro ou de outro modo já que "o nosso conhecimento do mundo tem historicidade" (FREIRE, 1996, p. 31).

Termino meu texto com um pequeno trecho de Beatriz Sarlo, saído de seu livro Viajes. Essas palavras me ajudam a compreender o que vivi durante quase uma semana na Argentina:

Hay tres elementos que se conjugan: el sujeto que viaja; el espacio desconocido; las modificaciones de ese sujeto por haber atravesado ese espacio. Si nunca dejé de pensar en esos viajes es porque les pertenezco de una manera radical: no son simplemente recuerdos, sino las formas que la experiencia me modifico a cada momento (SARLO, 2014, p.32).

Não somos necessariamente melhores professoras apenas por viajar ou participar de uma Expedição Pedagógica, mas é certo que viver uma experiência de deslocamento físico, pode nos ajudara fazer um deslocamento de ideias. E neste sentido, concordando com Sarlo, pode nos modificar.

\section{REFERÊNCIAS BIBLIOGRÁFICAS:}

ARCURI, Andrea e ROMERO, Teresa. Las expediciones pedagógicas en Argentina: relato de la experiência em la província de Neuquén. Neuquén, La Trama. Ano I. n.1, Maio 2014. p.11-22.

BARROS, Manoel de. Memórias Inventadas. as infâncias de Manoel de Barros. São Paulo: Editora Planeta, 2010.
BENJAMIN, Walter. Obras Escolhidas. Magia e técnica, arte e política: ensaios sobre literatura e história da cultura. São Paulo, Brasiliense, 1996.

BUARQUE. Cristovam. $A$ aventura da universidade. São Paulo: Ed. UNESP; Rio de Janeiro: Paz e Terra, 1994.

FORERO, Leonor Rodriguez Valbuena Nubia. El viaje como alternativa de formación em la expedición pedagógica. Revista Educación y Cultura "25 años del Movimiento Pedagógico". No. 77 - diciembre. Bogotá, D. C. FECODE. 2011.

FREIRE, Paulo. Pedagogia da autonomia: saberes necessários à pratica educativa. São Paulo, Paz e Terra, 1996.

IMEN, Pablo. As Expedições pedagógicas: construindo uma educação emancipadora a partir e para Nossa América. Revista Idelcoop. Buenos Aires, n. 212, 2014, p.115-133 Disponível em: http://www.idelcoop.org.ar/sites/default/fil es/revista/articulos/pdf/2014_63966765.p df>. Acesso em: 18 de nov de 2015.

LARROSA, Jorge. Nota sobre a experiência e o saber da experiência. Revista Brasileira de Educação, São Paulo, n.19, jan$\mathrm{abr} / 2002$, p. 20-28.

LARROSA, J. Pedagogia profana. Belo Horizonte: Autêntica, 1999.

LISPECTOR, Clarice. A paixão segundo G. H. Rio de Janeiro: Rocco, 1990.

MÁRQUES, Gabriel García. Vivir para contarla. Madrid, Editorial Leer-e, 2003.

MORAIS, Jacqueline de Fátima dos Santos; ARAÚJO, Mairce da Silva; ALVARENGA, Marcia Soares; TAVARES, Maria Tereza Goudard. Tecendo redes de extensão em São Gonçalo: a experiência do Vozes da Educação. Interagir: pensando a extensão, 
Rio de Janeiro, n. 16, p. 39-45, jan./dez. 2011. Disponível em:<http://www.epublicaco-

es.uerj.br/index.php/interagir/article/view/ 5333/3933>. Acesso em 15 nov. 2015.

MORIN, Edgar. Os sete saberes necessários à educação do futuro. São Paulo: Cortez; Brasília, DF: UNESCO, 2000.

OLIVEIRA, Dalila Andrade; FELDFEBER, Myriam. $O$ direito à educação na América Latina: uma análise das políticas educacionais na história recente do Brasil e da Argentina. In: OLIVEIRA, Dalila Andrade; FELDFEBER, Myriam; SOUZA Elizeu Clementino (Org.). Inclusão democrática $e$ direito à educação: desafios para a docência na América Latina. Belo Horizonte, Editora Unika, 2015.

ROMERO, Teresa. Las expediciones como território de memoria. Neuquén, La Trama. Ano I. n.1, Maio 2014. p.8-10.

ROSA, Guimarães. Grande sertão: veredas. Rio de Janeiro: Nova Fronteira, 1985. SANTOS, Boaventura de Souza. A crítica da razão indolente: contra o desperdício da experiência. São Paulo, Cortez, 2000.

SARLO, Beatriz. Viajes: De La Amazonia a las Malvinas. Ciudad Autónoma de Buenos Aires: SeixBarrial, 2014.

UNDA BERNAL, M. P.; MARTÍNEZ BOOM, A.; MEJÍA, M. R. El itinerario del maestro: de portador a productor de saber pedagógico. In: RORIGUEZ, A. et al. Veinte años Del movimiento pedagógico. Bogotá: Editorial Magisterio - Tercer Milenio. 2002. p. 61-94, 2002. 